\title{
Abuse of Authority and Hierarchical Communication
}

\author{
Guido Friebel \\ SITE (Stockholm) \\ and CEPR \\ Michael Raith \\ University of Chicago \\ and CEPR *
}

August 2001

*Correspondence address: Michael Raith, Graduate School of Business, University of Chicago, 1101

E. $58^{\text {th }}$ Street, Chicago, IL 60637, USA; email: michael.raith@gsb.uchicago.edu. A previous version of this paper circulated as Friebel and Raith (1999). We would like to thank Patrick Bolton, Mathias Dewatripont, Canice Prendergast and Gérard Roland for their encouragement and advice. The comments and suggestions of the editor and the referees substantially helped to improve the paper. We also benefited from many helpful comments by Marcel Boyer, Juan Carillo, Anne Chwolka, Jacques Crémer, Olivier Debande, Oliver Fabel, Allison Garrett, Bengt Holmström, Daniel Jansen, Ralf Körfgen, Jean-Jacques Laffont, Wolfgang Leber, Mikko Leppämäki, David Martimort, Eric Maskin, Paul Povel, Patrick Rey, Patrice Roussel, Martin Ruckes, Renata Schmit, Sikandar Siddiqui, Enrico Spolaore, Marc Stilke, Lars Stole, Jean Tirole and many seminar audiences. Any remaining errors are our own. Finally, we would like to thank the European Commission and the Communauté Française de Belgique for financial support. 


\title{
Abuse of Authority and Hierarchical Communication
}

\begin{abstract}
If managers and their subordinates have the same basic qualifications, then organizations can benefit from replacing unproductive superiors with more productive subordinates. In response to this threat, superiors may deliberately recruit unproductive subordinates, or abuse their personnel authority in other ways, in order to protect themselves. We show that the common practice of requiring intra-firm communication to pass through a "chain of command" can be an effective way of securing the incentives for superiors to recruit and develop the best possible subordinates. We discuss alternative ways to prevent the abuse of authority and general implications of our analysis for organizational design. We also present supporting evidence from the literature on human resource management and organizational behavior.
\end{abstract}

Keywords: Hierarchies, Strategic Recruiting, Internal Labor Markets, Abuse of Authority, Chain of Command

JEL-Codes: D82, J41, M12 


\section{Introduction}

"One of your jobs as a manager is to identify and promote new managers. Ideally, each new manager should be less qualified than you. Otherwise that new manager will try to take your job or make you look dumb. It's in your best interest to keep the talent pool as thin as possible, just as the people who promoted you have done..."

Dogbert's Top Secret Management Handbook (Adams 1996)

In many organizations, not only monitoring and control but also the flow of information are hierarchically structured. Employees are often discouraged from communicating with any higher-level managers other than their immediate superiors; that is, they are required to follow a "chain of command". Hierarchical communication is often interpreted as an optimal response to costly information processing. ${ }^{1}$ In this paper, we argue that hierarchical communication can also help to prevent conflicts between superiors and their subordinates over hiring and promotion decisions.

Positions at higher levels in organizations are typically accompanied by higher wages and additional benefits. Since organizations seek to fill positions with the most qualified employees, a subordinate may try to convince top management that she is better suited for her supervisor's position than the incumbent. Accordingly, managers sometimes see their subordinates as threatening.

Managers can usually counter this threat in various ways. They can, for instance, deliberately recruit weaker subordinates (we refer to this as "strategic recruiting") or refrain from developing employees under their purview. These responses directly decrease the productivity of the workforce and jeopardize the function of internal labor markets as a screening device for talent. The costs for the firm can be substantial. If it is infeasible to perfectly monitor supervisors, a firm must find other ways to prevent the abuse of authority.

1 The importance of a chain of command for the coordination of activities was first emphasized by Fayol (1916). Modern theories that derive communication structures from costs of communicating and processing information include Radner (1993) and Bolton and Dewatripont (1994). 
The key idea of how prohibiting "skip-level" communication, i.e. communication between subordinates and top management, can mitigate this problem is simple. A manager can be replaced by his own subordinate only if top management believes that the subordinate is better qualified than he is. To reach this decision, top management must have sufficiently reliable information about the subordinate's qualifications. If communication between the subordinate and top management is disrupted, this information is less likely to be available. While valuable information may be lost, subordinates will also be less threatening to their manager, reducing the manager's incentive to deliberately hire or develop unproductive employees.

The above argument is incomplete, however, because hiring unproductive subordinates reduces the performance of the manager's unit, which in turn reflects badly on the manager's ability. A manager who systematically hires unqualified people is unlikely to stay in his job for long. Since pressure to maximize the performance of his unit reduces a manager's incentive to abuse his authority, one could expect that the organization has no or less reason to restrict communication between his subordinates and top management. Our analysis shows that restricting communication can be optimal even when unit performance can be observed.

In the model there is a three-tier hierarchy consisting of a principal, a manager and a worker (Section 3). We assume that the principal appoints the manager and delegates to him the recruiting, training and development of the worker. The manager thus has the power to influence the productivity of the worker.

In large firms, explicit pay for performance is common among top executives but rare among the middle or lower ranks. Talented employees are typically rewarded by promotion to a higher-level job (see Baker, Jensen and Murphy 1988). Accordingly, we assume that the principal maximizes the net profit of the firm, while the manager and worker receive fixed wages. The principal initially does not know the abilities of the manager or the worker, but obtains information about them in the course of production, which may lead to job reassignments.

The principal obtains information in two ways. First, she can observe the outcome of 
a project jointly realized by the manager and the worker. This assumption captures the idea that the performance of the manager's sub-unit reveals information about both the manager's and the worker's productivity. Second, we assume that a worker who is more productive than her manager may try to convince the principal of this fact, hoping to be promoted. The ability to convey this information to the principal depends on how open the communication channel between the worker and the principal is, or in other words, to what extent a chain of command is followed.

In Section 4.1, we determine the equilibrium between the principal and the manager. The principal decides whether to retain or replace the manager for a second period of production, depending on the information she has available. If she learns that the worker is more productive than the manager, she will want to fire the manager and promote the worker. Otherwise, if observed performance is good, the principal will want to retain the manager; if performance is poor, she will prefer to fire him.

An unproductive manager then faces a conflict when hiring a worker. A productive worker increases the manager's odds of retaining his job because of good performance, but may also be able to inform the principal that she is more productive, and thus poses a threat to the manager. The more open the communication channel, the larger the threat, and the smaller the manager's incentive to hire a productive worker. Eventually, the manager may even actively seek an unproductive worker.

In Section 4.2, we examine the optimal degree of openness of communication. Allowing communication makes it easier to replace an unproductive manager with a more competent worker. But precisely this possibility may lead a manager to abuse his personnel authority by hiring and developing a less competent worker. We show that depending on the parameters of the model it can be optimal to prohibit communication entirely. But it can also be optimal to have an intermediate degree of openness or to allow completely open communication.

In Section 4.3, we show that if payments that depend on output are feasible, bonus or severance payments can alleviate the abuse of authority. It may still be optimal, however, to restrict communication. 
In Section 5, we present the predictions of our theory. Firms are more likely to restrict skip-level communication and thus give managers control over information flows (i) the more difficult it is to monitor managers' personnel decisions, and hence the more a firm needs to rely on managers in making personnel decisions; (ii) the more wages in an internal labor market are backloaded and shielded from the external labor market; and (iii) the more costly it is for managers to hire good subordinates. These results show that there are important complementarities between a firm's human resource policies, its production technology, and its rules of communicating.

Our formal analysis leaves two questions open, to which we turn in Section 6. First, how do alternative solutions to prevent the abuse of managerial authority compare to restricting skip-level communication? Allocating personnel decisions to a centralized personnel department, or monitoring managers' decisions closely, mitigates the problem but is in practice possible only to a limited extent. Restricting communication may save on monitoring costs. Restricting communication may also be more efficient than other ways to eliminate the threat subordinates pose to their superiors. These include promoting employees by seniority, giving superiors an employment guarantee (as in academia), or promoting employees into other units.

The second question relates to whether and how a firm can choose the degree of openness of communication. Drawing on the literature on organizational behavior, we argue that firms can influence the desired degree of openness of communication to a large extent.

To our knowledge, our paper is the first to analyze communication in multi-tier organizations from an incentive-theoretical perspective. We argue in Section 2 that this perspective is supported by the management and industrial psychology literature. That is, while hierarchical communication may help to reduce the costs of communication and information processing, this literature suggests that in practice, restrictions on skip-level communication have more to do with the concerns of managers who are bypassed than with information overload at higher levels. 


\section{Hierarchical Communication in Organizations}

The central claim of our paper is that there is a link between the potential abuse of managerial authority and the prevalence of hierarchical communication in organizations. This section presents evidence in support of this claim.

While the popular business press tends to advocate unrestricted communication as a way to achieve a maximum flow of ideas and information, most firms in practice maintain hierarchical communication patterns. That is, communication is typically confined to direct interaction between superiors and subordinates. ${ }^{2}$

This kind of hierarchical communication to some extent simply reflects the hierarchical structure of command and control, and even absent any organizational rules, one could expect most communication to follow the structure of the hierarchy. What is striking, however, is that many organizations have rules and norms that specifically discourage skip-level communication (cf. Wilson 1992, Gilsdorf 1994). It is the rationale for such rules that our theory seeks to explain.

A closer look at the management and organizational behavior literature suggests that middle managers are concerned about what their subordinates might say about them to top managers. This in turn causes a problem for the organization because middle managers have substantial power over their subordinates. Management scholars are aware of the strategic concerns of managers when communication between their subordinates and superiors is too open. Lillico (1972, p.45), for example, writes:

"Open-door policies, suggestion schemes, etc., can themselves be interpreted as bypassing methods commonly used by top management, ... These policies often generate suspicion among the bypassed middle management. How far can a subordinate go in pointing out his boss's mistakes - the man often in

\footnotetext{
${ }^{2}$ Perhaps as a consequence, almost all research on the determinants of upward communication focuses on direct supervisor-subordinate communication. Mention of skip-level communication is almost completely absent from this literature, cf. Wilson (1992). The only work we know of that looks at skip-level communication, that of Randolph and Finch (1977) and Wilson (1992), does not address to what extent the organizations studied encourage or discourage skip-level communication.
} 
charge of his progress and salary in the organization?"

Similarly, Baird (1977, p.267) writes:

"How can upward communication be improved? One common method is to short-circuit the normal chain of communication by skipping intermediate levels and communicating directly to someone several ranks removed. ... While this method often serves to improve communication accuracy, several dangers are present. ... the people who are bypassed by a subordinate may be resentful and judge the subordinate disrespectful or impertinent... If this method is to be used, care must be taken to .... reassure those employees who have been bypassed." 3

The quotes indicate that fear of managers' obstructive behavior rather than concerns for optimal information processing is what leads firms to restrict communication between employees and higher-level superiors.

The experience with "360 degree feedback" and "upward appraisals" provides further evidence in support of our theory. In the late 1980's, many management theorists recommended involving subordinates in the evaluation of managers' performance. Firms have been reluctant, however, to implement upward appraisals. In a survey of 305 firms (Bettenhausen and Fedor 1997), only 9\% reported to use upward appraisals. The dangers associated with upward appraisals are evident:

"A potentially negative aspect of an employee rating a supervisor is the possibility of retaliation. Supervisors who are aware that subordinates have given them negative ratings may punish them by assigning undesirable tasks, withholding salary increases, or generally making the employees' jobs more difficult.

3 The same argument is also made in the non-academic management literature, see for example Falconi (1997): "[the] most important [problem with open-door policies is that] — encouraging employees to avoid using the chain of command is demoralizing to supervisors. Sure, actually talking to the CEO or some other member of senior management may make the employee low down on the ladder feel good, but how does the supervisor of that employee feel? Isn't he an employee too?" Similar comments pointing out "demoralizing" effects on middle managers who are bypassed are common. Most, however, do not pin down exactly what the resulting problems for the organization (not just the managers) are. 
(Brutus, Fleenor, London 1998). ${ }^{4}$

Hence, it is today widely believed that upward appraisals should be used only for purposes of feedback and development of the superiors' skills rather than as a basis for their pay, promotion, or termination (Dalton 1998). There is a consensus that upward appraisals work best if an organization is characterized by a flat hierarchy, participatory management, and a good corporate climate. If the scope for conflict between managers and their subordinates is large, then upward appraisals, which represent a form of institutionalized violation of the chain-of-command principle, should be avoided - in line with our theory.

\section{The Model}

We consider an organization that consists of three individuals in a hierarchical relationship: a principal ("P", female), a manager ("M", male), and a worker ("W", female).

\subsection{Timing}

There are two periods, 1 (stages 1 through 5 of the game) and 2 (stages 6 through 8 ). In each period, $\mathrm{P}$ and $\mathrm{M}$ make personnel decisions, which are followed by the production of output, and in period 1 by a stage in which $\mathrm{W}$ may communicate with $\mathrm{P}$.

1. P hires $M$. With probability $\alpha_{0}, \mathrm{M}$ is productive ("good"), and with probability $1-\alpha_{0}$, he is unproductive ("bad"). The type "good" or "bad" refers to the quality of the match between person and job, and is is unknown to $\mathrm{M}$ before he is hired. As soon as $\mathrm{M}$ starts his job, he learns his type.

2. $M$ chooses $\alpha \in[0,1]$ (while recruiting or training $W$ ), which affects $W$ 's productivity: with probability $\alpha, \mathrm{W}$ is good, and with probability $1-\alpha$ she is bad. See Section 3.2 below for details.

\footnotetext{
${ }^{4}$ A practitioner, Kiechel (1989) writes: "Even fans of the practice admit that it's tricky. Do not try it, for instance, in an authoritarian organization, one being downsized, or any place with minimal communication up and down: it will only feed the general paranoia. Administered incorrectly, the process may leave subordinates open to reprisals from you know whom."
} 
3. $M$ and $W$ observe each other's type.

4. $M$ and $W$ jointly produce the first-period output $y$, which can be observed by $\mathrm{P}$, but is not contractible. The production technology is described in Section 3.3.

5. W signals productivities to $P($ see Section 3.4$)$. If the team is of the form $(\mathrm{M}=\mathrm{bad}$, $\mathrm{W}=$ good), $\mathrm{W}$ can send a non-contractible signal to $\mathrm{P}$ which perfectly reveals the types of $\mathrm{M}$ and $\mathrm{W}$ without cost and in a credible way. This information reaches $\mathrm{P}$ only with a probability $\phi \in[0,1]$ which captures the openness of skip-level communication between $\mathrm{W}$ and $\mathrm{P}: \phi=1$ represents completely open communication; $\phi=0$ corresponds to the strict enforcement of a "chain of command".

6. $P$ retains or replaces $M$. Depending on $y$ and her communication with $\mathrm{W}, \mathrm{P}$ chooses to either retain the current $\mathrm{M}$, fire $\mathrm{M}$ and hire a new one from outside, or fire $\mathrm{M}$ and promote $\mathrm{W}$. The latter is an option because we assume that $\mathrm{W}$ is eligible for the job of M. In particular, $\mathrm{W}$ is good as an $\mathrm{M}$ if and only if she was good as a $\mathrm{W} .{ }^{5}$

7. $M$ retains or replaces $W$. We assume that this not a strategic decision: a retained M, who knows W's type, acts in the firm's interest and retains W if she is good and hires a new $\mathrm{W}$ if she is bad. Any newly hired $\mathrm{W}$ is good with probability $\alpha_{0}$, regardless of whether the M hiring her was retained, recently promoted, or just hired.

8. The second-period output is realized. Only $\mathrm{P}$ and $\mathrm{M}$ are players in a game-theoretic sense. Each chooses one action in the course of the game, $\mathrm{M}$ at stage 2, when he hires $\mathrm{W}$, and $\mathrm{P}$ at stage 6 , when she decides whether to retain $\mathrm{M}$. All other moves in the game are dominant actions.

\subsection{Recruitment and Personnel Development}

When $\mathrm{M}$ chooses the probability $\alpha$ of having a good $\mathrm{W}$, he incurs the following cost:

$$
C(\alpha)=k_{0} \alpha^{2}+k_{1}(1-\alpha)^{2}
$$

\footnotetext{
${ }^{5}$ Alternatively, we could assume that a person who is good as a $\mathrm{W}$ is also good as an $\mathrm{M}$ with some probability $\beta \leq 1$. None of our results change under this weaker assumption, except that we need to specify a lower bound to $\beta$.
} 
The first term represents the cost of M's productive effort to increase W's expected productivity. This cost is scaled by $k_{0}$ and is convex in M's desired probability of hiring a good W. The second term represents the costs of influence effort that $M$ may want to exert. We assume that P monitors M's personnel decisions to an extent measured by $k_{1}$. The costs of influence effort are convex in $1-\alpha$ (the probability of having a bad W), because it is easy for $\mathrm{M}$ to get P's approval for a candidate with outstanding credentials, but difficult to get P's approval of an applicant that looks rather weak. ${ }^{6}$

For future reference, denote the optimal probabilities chosen by a good and a bad M as $\alpha_{g}$ and $\alpha_{b}$. We assume that

$$
\alpha_{0} \geq \alpha_{b}^{0}:=\frac{2 k_{1}+\delta\left(q_{b g}-q_{b b}\right)\left(r_{M}-r_{W}\right)}{2\left(k_{0}+k_{1}\right)}
$$

to exclude a situation that does not make sense economically. Recall that $a_{0}$ is the probability with which $\mathrm{P}$ hires a good M. As we will show in Proposition 1, $\alpha_{b}^{0}$ represents the highest level of $\alpha_{b}$ in any possible equilibrium of the game. Without assumption (2), the worker hired by M might be good (and therefore also good as an M) with a higher probability (from P's perspective) than $\mathrm{M}$ himself, in which case $\mathrm{P}$ might like to promote $\mathrm{W}$ and replace $\mathrm{M}$ even without any communication from $\mathrm{W}$ to $\mathrm{P}$. Assumption (2) is necessary though not sufficient to rule out this situation.

\subsection{Joint Production by $\mathrm{M}$ and $\mathrm{W}$}

The output $y$ produced by $\mathrm{M}$ and $\mathrm{W}$ is random and takes the values 0 or 1 . We disregard any moral-hazard problems related to production; the probability of $y=1$ only depends on the productivities of $\mathrm{M}$ and $\mathrm{W}$. Let $q_{g g}=\operatorname{Prob}\{y=1 \mid \mathrm{M}=\operatorname{good}$ and $\mathrm{W}=\operatorname{good}\}$, and define $q_{g b}, q_{b g}$ and $q_{b b}$ analogously. Thus, the firm's technology is completely characterized by the vector $\mathbf{q}=\left(q_{g g}, q_{g b}, q_{b g}, q_{b b}\right)$.

We assume that $q_{g g} \geq q_{g b} \geq q_{b g} \geq q_{b b}$. The first and the last inequalities state that the expected output is an increasing function of the productivities of $\mathrm{M}$ and $\mathrm{W}$. The second

${ }^{6}$ Similarly, if $\mathrm{M}$ is expected to invest in the training and development of $\mathrm{W}$, he may have to explain himself if he fails to meet this expectation. 
inequality states that $\mathrm{M}$ is at least as important for production as $\mathrm{W}$. We also assume that $q_{g g}-q_{g b} \geq q_{b g}-q_{b b}$, which means that a good manager values having a good rather than a bad worker more highly than does a bad manager. In other words, M's and W's productivities are complementary.

\subsection{Structure of the Signal from $\mathrm{W}$ to $\mathrm{P}$}

In formal terms, $\mathrm{P}$ receives a signal $z$ that takes the value ' $\mathrm{d}$ ' (types are disclosed) if $\mathrm{W}$ successfully signals to her that $\mathrm{W}$ is good and $\mathrm{M}$ bad. If either the production team is of another form, or if W's signal does not get through to P, the signal $z$ takes the value 'c' (types are concealed). It is always optimal for $\mathrm{W}$ to send a signal if she is better than $\mathrm{M}$ because she can never lose, but possibly gain by being promoted. This signal structure can be seen as resulting from the following more primitive assumptions:

1. The signal from $\mathrm{W}$ to $\mathrm{P}$ is not contractible. That is, the evidence $\mathrm{W}$ produces cannot be used in court, and can therefore not be the basis of an explicit contract.

2. W can hide her information, but not forge it.

3. W can signal only rank-order (relative) information about M's and W's productivities, and not information about M's or W's absolute productivity. This assumption is familiar from the literature on tournaments (cf. Lazear and Rosen 1981).

4. W sends a signal to $\mathrm{P}$ if and only if her expected benefit from doing so is positive.

Moreover, to keep the model tractable, we assume that only $\mathrm{W}$, not $\mathrm{M}$, can communicate productivities to $\mathrm{P}$. To illustrate these assumptions, suppose M's and W's joint project involves the purchase of securities. If $\mathrm{W}$ suggested the purchase of one type, but M decided to purchase another type, and it turns out that W's investment would have been more profitable, $\mathrm{W}$ can ex post convince $\mathrm{P}$ of this, by producing memos or other internal documents as evidence. Such evidence conveys information only about the relative, not the absolute abilities of $\mathrm{M}$ and $\mathrm{W}$. It is also unrealistic to assume that $\mathrm{P}$ and $\mathrm{W}$ can write a contract that compensates $\mathrm{W}$ for proving that her suggested investment was better than M's. 


\subsection{Payoffs}

Our assumptions about the players' payoffs are based on Baker, Jensen and Murphy's (1988) empirical observations that "explicit financial rewards in the form of transitory performance-based bonuses seldom account for an important part of a worker's compensation", and that "most of the average increases in an employee's compensation can be traced to promotions and not to continued service in a particular position ... Promotions are used as the primary incentive tools in most organizations." An implication of this observation is that reaching a higher level in a hierarchy is associated with a rent or quasi-rent. $^{7}$

Motivated by these stylized facts, we assume that the base wages $\mathrm{M}$ and $\mathrm{W}$ receive in each period are fixed and exogenous, and are given by $r_{M}>r_{W}>0$. Since it is impossible to write contracts that specify payments to $\mathrm{M}$ or $\mathrm{W}$ contingent on realizations of $y$ or $z$, the wages $r_{M}$ and $r_{W}$ represent the two agents' total compensation in each period. If $\mathrm{M}$ is fired after the first period, he receives a wage of less than $r_{M}$ in a different job; that is, he loses a rent. For simplicity, let M's wage in an alternative job be $r_{W} \cdot{ }^{8}$ Our assumptions imply that M strictly prefers keeping his job to losing it; and W strictly prefers promotion over staying in her job. The manager chooses $\alpha$ to maximize his discounted second-period payoff, net of his recruiting costs

$$
U(\alpha)=r_{M}-C(\alpha)+\delta\left\{P_{r e t}(\alpha) r_{M}+\left[1-P_{r e t}(\alpha)\right] r_{W}\right\},
$$

where $P_{\text {ret }}(\alpha)$ is the probability that M is retained, as a function of $\alpha$ and his own type; and $\delta$ is the discount factor.

The principal maximizes the firm's profit, i.e. the expected present value of outputs produced in the two periods, net of the monetary compensation for $\mathrm{M}$ and $\mathrm{W}$. In addition,

7 Theories that predict backloaded age-wage profiles include Salop and Salop (1976) and Lazear (1981). To the extent that pay increases are administered through promotions, backloaded wages imply that pay is correlated with the rank in a hierarchy. Theories that directly predict wages that increase in rank include Lazear and Rosen (1981) and Qian (1994).

${ }^{8} \mathrm{We}$ also rule out that the $(\mathrm{M}, \mathrm{W})$-unit of the firm is sold to $\mathrm{M}$, i.e. that $\mathrm{M}$ becomes the residual claimant of this unit. 
we allow in our model that there are positive effects of open communication unrelated to the detection of bad Ms, captured by the assumption that the firm's expected profit increases in $\phi$ at rate $\omega \geq 0$.

Formally, P's beliefs about the composition of the (M,W)-team are characterized by a probability distribution over the four possible teams $(\mathrm{g}, \mathrm{g}),(\mathrm{g}, \mathrm{b}),(\mathrm{b}, \mathrm{g})$, and $(\mathrm{b}, \mathrm{b})$. Let (the quadruple) $\mathbf{p}_{\mathbf{1}}$ denote $\mathrm{P}$ 's beliefs about the team in the first period, and let $\mathrm{E}\left(\mathbf{p}_{\mathbf{2}}\right)$ be her expected beliefs in period 2. Since $\mathbf{p}_{\mathbf{2}}$ is the P's belief at the beginning of period 2 , we take the expected value in looking at the ex-ante expected profit. Normalizing the payoff associated with $y=1$ to 1 , the firm's expected profit can be written as

$$
\pi=\mathbf{p}_{\mathbf{1}} \mathbf{q}+\delta E\left(\mathbf{p}_{\mathbf{2}}\right) \mathbf{q}+(1+\delta) \omega \phi-(1+\delta)\left(r_{M}+r_{W}\right)
$$

We allow $\delta$ to exceed 1 , since the second period might represent a discounted future that may be more important than the first period.

\section{Equilibrium and Optimal Openness of Communi- cation}

First, we derive the equilibrium for the game between $\mathrm{P}$ and $\mathrm{M}$. We then analyze how an organizational planner would optimally choose the level of openness $\phi$, and finally discuss the robustness of our results when monetary incentives are feasible.

\subsection{Equilibrium}

In its reduced form, the model is a simple sequential game involving $\mathrm{M}$ and $\mathrm{P}$ with incomplete information on part of P. There are two types of Ms, good ones and bad ones. $\mathrm{P}$ knows the distribution of types (given by $\alpha_{0}$ ) but cannot observe the type of $\mathrm{M}$ she hires. M chooses an unobservable probability that $\mathrm{W}$ is good, depending on his own type. Upon observing the team's output and W's message to P, P chooses to retain M, hire a new one, or promote $\mathrm{W}$. 


\section{Proposition 1 If}

$$
\begin{aligned}
& q_{g g}=1 \quad \text { and } \\
& q_{g g}-q_{g b}>q_{b g},
\end{aligned}
$$

there exists a unique Bayesian Nash equilibrium. It has the following properties: (i) a good $M$ chooses

$$
\alpha_{g}=\min \left\{\frac{2 k_{1}+\delta\left(q_{g g}-q_{g b}\right)\left(r_{M}-r_{W}\right)}{2\left(k_{0}+k_{1}\right)}, 1\right\}
$$

(ii) a bad $M$ chooses

$$
\alpha_{b}=\max \left\{\alpha_{b}^{0}-\frac{\delta \phi q_{b g}\left(r_{M}-r_{W}\right)}{2\left(k_{0}+k_{1}\right)}, 0\right\},
$$

and (iii) upon observing $z=d, P$ promotes $W$; upon observing $z=c$ and $y=0$, P hires a new $M$; and upon observing $z=c$ and $y=1, P$ retains $M$.

(All proofs are in the Appendix.) Conditions (5), (6) are sufficient but not necessary for the equilibrium to have the properties described in Proposition 1. The precise necessary and sufficient conditions for these properties to hold are conditions (16)-(19) in the proof. If these conditions do not hold, a unique equilibrium still exists for any combination of parameters. Their properties are different, as we explain below and in the proof.

To understand P's best response to M's strategy, consider the effects of the signals $y$ and $z$ on P's updated belief that $\mathrm{M}$ is good. First, upon observing $y=1$, P's posterior about $\mathrm{M}$ exceeds her prior, while if $y=0$, the opposite is the case. Second, if $z=d, \mathrm{P}$ knows for sure that $\mathrm{M}$ is bad, which implies that $z=c$ is good news about $\mathrm{M}$. If $z=d, \mathrm{P}$ promotes $\mathrm{W}$ because a good $\mathrm{M}$ is more valuable than a good $\mathrm{W}$. The principal's inference is more complicated if $z=c$. The parameter conditions of Proposition 1 ensure that in this case P's decision about $\mathrm{M}$ depends on the observed output: if $y=1$, she retains $\mathrm{M}$, whereas if $y=0$, she hires a new one.

More precisely, a low output $(y=0)$ is negative information about M, but observing $z=c$ is favorable news. Condition (5) ensures that the first effect dominates: if $q_{g g}=1$, then upon observing $y=0, \mathrm{P}$ knows that $\mathrm{M}$ and $\mathrm{W}$ cannot both be good, and in this case it is more likely that $\mathrm{M}$ is bad than that $\mathrm{B}$ is bad. Thus, low output is sufficiently bad news about $\mathrm{M}$ to outweigh the positive effect of $z=c$ on P's updated belief, inducing $\mathrm{P}$ 
to hire a new M. Conditions(5) and (6), in conjunction with (2), also ensure that $\mathrm{P}$ would never want to promote $\mathrm{W}$ if $z=c .^{9}$

M's best response is to choose the $\alpha$ that maximizes his payoff (3), anticipating P's response to $y$ and $z$. Since a good M (for whom always $z=c$ ) is retained if and only if $y=1$, the probability of being retained for him is $P_{r e t}(\alpha)=\alpha q_{g g}+(1-\alpha) q_{g b}$. Substituting this expression into (3) leads to the expression for $\alpha_{g}$ stated in the proposition. A bad M, in contrast, is fired whenever $y=0$, but also if $z=d$, which happens with probability $\phi$ if $\mathrm{W}$ is good. Hence, the probability of being retained for him is $P_{r e t}(\alpha)=\alpha(1-\phi) q_{b g}+$ $(1-\alpha) q_{b b}$, which leads to the expression for $\alpha_{b}$ in Proposition 1.

Comparing $\alpha_{g}$ and $\alpha_{b}$, we find that for any $\phi$, a bad M chooses a lower probability than a good M, for two reasons: 1. Because of our complementarity assumption, a good $\mathrm{W}$ is less valuable to a bad $\mathrm{M}$ than to a good one. 2. A bad $\mathrm{M}$ faces a risk of being replaced by a good W, which further reduces M's incentive to find a good W. His $\alpha_{b}$ is decreasing in $\phi$ : more open communication between $\mathrm{W}$ and $\mathrm{P}$ exposes $\mathrm{M}$ to greater risk and therefore distorts his incentives.

Notice also that when $\phi \geq 1-q_{b b} / q_{b g}$, M actively engages in abusive behavior in the sense of choosing an $\alpha$ below the level that minimizes $C(\alpha)$. Here, M's risk of being exposed by a better $\mathrm{W}$ is so large that $\mathrm{M}$ prefers to incur the cost of getting $\mathrm{P}$ 's approval in trying to hire a bad W. If, in contrast, $\mathrm{P}$ does not control M's personnel decisions at all $\left(k_{1}=0\right)$, then $\alpha_{b}=0$ for any $\phi \geq 1-q_{b b} / q_{b g}$.

Other equilibria: If conditions (5) or (6) do not hold, the resulting equilibrium is still unique for any set of of parameters. We can distinguish two types of equilibria: first, there is an equilibrium in which $\mathrm{P}$ always retains $\mathrm{M}$, irrespective of output, as long as $z=c$. A bad M would then have no incentive to hire a good W, since a good W only threatens M's position. It follows that when the performance of M's unit is not sufficiently informative of M's productivity, the problem of strategic recruiting is most severe. Throughout the

\footnotetext{
${ }^{9}$ Notice that (2) together with (8) implies that $\alpha_{0} \geq \alpha_{b}$, whereas (6) is somewhat stronger than the complementarity assumption $q_{g g}-q_{g b}>q_{q b g}-q_{b b}$ imposed earlier.
} 
paper, we assume that output is sufficiently informative to influence P's decision not because the opposite case is unrealistic, but to make clear that restricting communication may be desirable even if performance is observable.

Second, there are equilibria in which $\mathrm{P}$ promotes $\mathrm{W}$ upon observing $y=0$ or $y=1$, although $z=c$ (Condition (2) is not sufficient to rule them out). We have argued that such equilibria are economically unrealistic, for they imply that $\mathrm{P}$ would in effect prefer to delegate hiring of the second-period $M$ to the first-period M, instead of hiring $M$ herself.

\subsection{Optimal Choice of $\phi$}

An increase in the openness of communication has three different effects on the net profit of the firm (or unit): First, there is a direct positive effect because a bad $\mathrm{M}$ is detected with higher probability. Second, a bad M faces a greater risk of being revealed by a good $\mathrm{W}$ and therefore reduces $\alpha_{b}$, which decreases expected output. Finally, captured by $\omega$, there may be positive effects of open communication unrelated to the detection of bad Ms. Taken together, these three effects imply the following:

Proposition 2 Under the assumptions of Proposition 1, the firm's expected equilibrium profit is concave in $\phi$.

To see this, notice that $\phi$ affects the expected profit both directly (the first and third effects discussed above), and indirectly through $\alpha_{b}$ :

$$
\frac{d \pi}{d \phi}=\frac{\partial \pi}{\partial \phi}+\frac{\partial \pi}{\partial \alpha_{b}} \frac{\partial \alpha_{b}}{\partial \phi}
$$

Since expected profit is linear in $\phi$, and $\alpha_{b}$ is a linear function of $\phi$, the second-order derivative simplifies to $d^{2} \pi / d \phi^{2}=\left(\partial^{2} \pi / \partial \alpha_{b} \partial \phi\right)\left(\partial \alpha_{b} / \partial \phi\right)$. The cross-derivative of $\pi$ with respect to $\phi$ and $\alpha_{b}$ is positive: other things equal, a larger $\alpha_{b}$ increases the probability of having a team with a bad $\mathrm{M}$ and a good $\mathrm{W}$ in the first period, which in turn increases the firm's marginal value of detecting a bad M, and hence the marginal value of more openness. With $\alpha_{b}$ decreasing in $\phi$, it then follows that expected profit is concave in $\phi$.

The firm's profit $\pi(\phi)$ can be increasing, decreasing or (since $\pi(\phi)$ is concave) humpshaped in $\phi$. Depending on which case obtains, it can therefore be optimal to have 
completely open or completely closed communication between $\mathrm{W}$ and $\mathrm{P}$, or to have an intermediate degree of openness $(0<\phi<1)$. The corresponding parameter conditions are difficult to interpret. However, the following proposition identifies conditions for open communication to be optimal.

Proposition 3 Suppose the assumptions of Proposition 1 hold. If $k_{1}=0$ and $\omega=0$ and $\delta \leq 1$, then $\pi(0)>\pi(1)$; i.e. complete enforcement of a chain of command is more profitable than completely open communication.

The implication of Proposition 3 is that full openness can be optimal for the firm only if

(i) P exerts some control over M's personnel decisions $\left(k_{1}>0\right)$, or

(ii) future production (and hence detecting a bad M in period 1) is particularly valuable $(\delta>1)$, or

(iii) there is some benefit of openness unrelated to detecting bad Ms $(\omega>0)$.

The intuition for this result is that unless $\mathrm{P}$ exerts some direct control over M's hiring decisions, a bad $\mathrm{M}$ will definitely hire a bad $\mathrm{W}$ if communication is completely open. In this case, no signaling from $\mathrm{W}$ to $\mathrm{P}$ will occur because a bad $\mathrm{W}$ cannot credibly tell on M. The same is true with completely closed communication, except that here, $\mathrm{M}$ has an incentive to hire a good W. Closed communication is therefore preferred unless there are other advantages of having open communication, or if future production is so important that $\mathrm{P}$ wants a bad $\mathrm{M}$ to hire a bad $\mathrm{W}$, in order to maximize the chance of getting rid of him after one period of production because of bad performance.

\subsection{Monetary Incentives}

We have seen above that if $\mathrm{P}$ can observe an output signal that is informative of M's productivity, a bad M's incentive to abuse his authority is alleviated, although generally not eliminated. It is natural to ask whether an output signal is even more useful if M's compensation can be conditioned on it. We therefore now assume that the output $y$ is 
contractible, while continuing to take the base wages $r_{M}$ and $r_{w}$ as given. Two types of contingent payments are conceivable: a bonus that is paid whenever performance is good, and a severance payment that is made if performance is good but $\mathrm{M}$ is fired nevertheless.

Severance payments: The principal can offer a contract stipulating a severance payment $s$ that is paid only if $\mathrm{M}$ is fired and $y=1$. Such a contract insures a bad M against losing his job because of communication between $\mathrm{W}$ and $\mathrm{P}$, and should reduce the risk of abuse of authority. ${ }^{10}$ How does the feasibility of severance payments affect the firm's optimal communication structure compared to our preceding analysis?

If a bad M receives $s$ if he is fired when $y=1$, then his payoff changes from (3) to

$$
U(\alpha)=r_{M}-C(\alpha)+\delta\left[P_{r e t}(\alpha) r_{M}+\left(1-P_{r e t}(\alpha)\right) r_{W}\right]+\alpha \phi q_{b g} s
$$

where $P_{r e t}$ is unchanged (cf. Proposition 1). The resulting optimal effort $\alpha_{b}$ is

$$
\alpha_{b}=\frac{2 k_{1}+\delta\left((1-\phi) q_{b g}-q_{b b}\right)\left(r_{M}-r_{W}\right)+\phi q_{b g} s}{2\left(k_{0}+k_{1}\right)} .
$$

Thus, $\alpha_{b}$ is increasing in $s$ for any $\phi$ and any $s>0$. With a severance payment, a bad $\mathrm{M}$ has less to lose if he is revealed by a good $\mathrm{W}$ and is subsequently fired. This increases M's incentive to exert effort.

Offering severance pay has two effects for P: expected profit increases in $s$ through its effect on $\alpha_{b}$. This effect is proportional to $r_{M}-r_{W}$, i.e. the loss to $\mathrm{M}$ if he is fired. On the other hand, $s$ is a direct cost that must be paid with probability $\left(1-\alpha_{0}\right) \alpha_{b} \phi q_{b g}$, i.e. the probability that $\mathrm{M}$ is bad, $\mathrm{W}$ is good, $z=d$ and $y=1$. A variety of cases can occur:

(i) By offering $s=\delta\left(r_{M}-r_{W}\right)$, P can completely eliminate abusive behavior of $\mathrm{M}$. Then, $\alpha_{b}$ has the same value that it would have if $\phi=0$, and does not depend on $\phi$.

10 Three remarks: First, abusive behavior may only arise because a bad M risks to lose his job although $y=1$ - if $z=d$, which is possible only if $\mathrm{W}$ is good. Second, an alternative setup is to assume that output cannot be verified, but that severance payments can be specified for the case that $\mathrm{M}$ is fired and W subsequently promoted (since without W's signal, $\mathrm{P}$ would never have an incentive to promote W). The results obtained under this rather unrealistic assumption differ only slightly from those presented here. Third, notice that $\mathrm{P}$ would never want to pay severance regardless of output, as this would only reward bad performance and reduce the incentives for both a good and a bad M to hire a good W. 
Without a negative effect of $\phi$ on $\alpha_{b}$, it follows from the analysis in Section 4.2 that the firm's profit is increasing in $\phi$, i.e. open communication is optimal. Whether this severance pay is profitable for the firm depends on $r_{M}-r_{W}$ and $k_{1}$. In particular, $r_{M}-r_{W}$ must be sufficiently small so that if $z=d$ and $y=1, \mathrm{P}$ would actually want to fire $\mathrm{M}$ and promote $\mathrm{W}$, instead of just retaining $\mathrm{M}$ to avoid paying $s$.

(ii) If $r_{M}-r_{W}$ exceeds a critical value, then $\mathrm{P}$ does not offer any severance, as the direct expected costs always exceed the benefit of slightly increasing $\alpha_{b}$. The results of Section 4.2 then apply unchanged.

(iii) Between these two extreme cases lies an intermediate range of $r_{M}-r_{W}$ where $\mathrm{P}$ offers some severance that increases M's effort without eliminating abusive behavior completely, and where communication is more open.

Bonus payments: Suppose $\mathrm{P}$ offers $\mathrm{M}$ a bonus $b$ for high output in order to increase his incentive to choose a good W. In our two-period model, such a bonus is very similar to a raise of $r_{M}$ in the second period, since $\mathrm{M}$ is also retained only if $y=1$. (Such a raise could be seniority-based, i.e. be offered only to a retained $\mathrm{M}$, even under the noncontractibility assumptions of Section 4.) The only difference between $b$ and $\Delta_{r}$ is that if $z=d$ and $y=1$, a bad $\mathrm{M}$ would receive the bonus but not the raise. This means that a bonus is equivalent to a severance payment combined with a raise of the same discounted magnitude. Formally, we have:

Proposition 4 Let $\pi\left(s, b, \Delta_{r}\right)$ denote the firm's expected profit as a function of a severance payment $s$, a bonus $b$ and a raise $\Delta_{r}$ for a retained $M$. Then $\delta(d \pi / d b)=d \pi / d \Delta_{r}+$ $\delta(d \pi / d s)$.

Proposition 4 implies that when a severance payment is feasible and raising the manager's compensation is not desired, a severance payment is a better targeted instrument than a bonus payment. On the other hand, when raising the manager's compensation is desired, a suitable bonus can be superior to a raise because it implicitly includes a severance payment and hence provides better incentives for the manager's personnel decisions. 


\section{Comparative Statics and Predictions}

Our theory leads to a number of predictions about the openness of communication in firms. The first prediction is implicit in the setup of our model: firms are more likely to restrict skip-level communication when subordinates are eligible for their superior's position, because that is when subordinates have the greatest incentive (and the necessary credibility) to communicate negative information about their superiors to higher-level managers. For example, skip-level communication is more likely to be restricted for line managers, where this condition if often satisfied, than for staff employees who are supervised by line managers. The comparative statics of the model leads to additional empirical predictions:

Proposition 5 Under the assumptions of Proposition 1, the firm's optimal level of $\phi$ is:

(i) increasing in $k_{1}$;

(ii) decreasing in $r_{M}-r_{W}$;

(iii) increasing in $k_{0}$ if $\omega>0$, otherwise independent of $k_{0}$;

(iv) decreasing in $\alpha_{0}$ if $\omega=0$, but increasing in $\alpha_{0}$ if $\omega$ is sufficiently larger than 0 ;

(v) increasing in $\omega$.

Part(i): More control by $\mathrm{P}$ over M's personnel decisions raises the costs of abusive behavior and leads to higher levels of $\alpha_{b}$ for any $\phi$. A higher $\phi$ is then optimal. The more costly it is to monitor supervisors' personnel decisions, the greater the extent to which personnel decisions must be delegated to managers (cf. also the discussion in Section 6.1 below). Often, the extent of managerial involvement in personnel decisions can be measured rather precisely (see for example Pinfield 1995, pp. 316-320). Moreover, it is also likely to be correlated with measures of task uncertainty and the degree of job formalization, which have also been used in the literature, cf. Wilson (1992).

Part (ii): The difference $r_{M}-r_{W}$ affects the optimal $\phi$ through $\alpha_{b}$. If $r_{M}-r_{W}$ decreases, $\alpha_{b}$ decreases in $\phi$ at a smaller rate. Trading off the benefits of openness and the loss due to abuse of authority, $\mathrm{P}$ therefore chooses a larger $\phi$. Employees (except for those at the 
lowest levels) earn rents if a firm's wages are backloaded either for incentive (Lazear 1981) or selection (Salop and Salop 1976) reasons. Internal labor markets with this feature are characterized by wages that do not vary sensitively with wages on the external labor market. Moreover, employees must expect to spend some time in the firm, and to have the opportunity to get promoted into better-paid positions. Consequently, restrictions on communication are more likely to be observed (i) the less closely wages are related to the external market (see Bertrand 1998, who measures this relationship directly), (ii) the longer employees' job tenures are, and (iii) the more a firm fills vacancies by promoting employees from within. ${ }^{11}$

Part (iii): An increase in the marginal cost of productive effort, i.e. the marginal cost of recruiting or developing a good W, leads to a direct decrease in (a bad) M's effort. The firm would want to compensate for this by decreasing $\phi$ to provide better insurance to M. On the other hand, an increase in the marginal cost of productive effort also makes M less sensitive to changes in $\phi$, implying that the firm can afford to increase $\phi$. When $\omega=0$, these two effects cancel each other exactly. With $\omega>0$, the more realistic case, the second effect dominates, so that an increase in recruiting costs is accompanied by more openness. Our prediction is that organizations in which recruiting costs are high also have more open communication. Hiring costs can be measured, and expressed for example as a percentage of annual compensation.

Part (iv): a larger $\alpha_{0}$ is tantamount to a lower probability of recruiting a bad M. There are two effects: first, given $\alpha_{b}$, $\mathrm{P}$ is now less concerned about M's potential abuse of authority, which would suggest to increase $\phi$. On the other hand, if the probability of having a bad M decreases, P's benefit from detecting a bad M decreases too, which would suggest to decrease $\phi$. If $\omega=0$, i.e. without any other benefit of openness for the firm, this second effect outweighs the first, implying that an increase in $\alpha_{0}$ leads to a decrease in the optimal $\phi$. If, however, $\omega$ exceeds some minimal level, then the effect is reversed: a higher probability of recruiting a good $M$ implies that the firm can now

${ }^{11}$ A corollary of this prediction is that a firm's transition from a shielded internal labor market with backloaded wages to more market-based wages (for evidence of this trend, see Bertrand 1998) is likely to be accompanied by a shift towards more open communication. 
afford more openness. In this case, firms that spend more effort on recruiting their middle management can also afford more open communication, because good managers have less to fear from good subordinates. - Part $(v)$ is obvious.

The effects of changes in the $\delta$ on the optimal $\phi$ are ambiguous, since we have assumed that the discount factors are the same for both $\mathrm{P}$ and $\mathrm{M} .{ }^{12}$ For example, an increase in the firm's discount factor makes detecting a bad M more important for the firm, which suggests an increase in $\phi$. On the other hand, an increase in M's discount factor raises the value to $\mathrm{M}$ of keeping his job. While $\alpha_{g}$ would increase, $\alpha_{b}$ might decrease, and it may be optimal to reduce $\phi$.

Similarly, the effects of changes in $\mathbf{q}$ on the optimal $\phi$ are ambiguous. The obvious conjecture, for instance, would be that the more informative observed output is (reflected in some measure of the spread of the $q_{i j}$ ), the more a bad M benefits from having a good $\mathrm{W}$, hence the greater $\alpha_{b}$, and hence the greater the degree of openness $\phi$ that the firm can afford. More generally, there is an "output effect" of the model parameters on the optimal $\phi$ : since restricting $\phi$ only serves to induce a bad M to hire a good W, changes that induce an increase in $\alpha_{b}$ lead the firm to increase $\phi$. There is a second, "detection" effect, however, that goes in the opposite direction. If future profits are important, then conditional on having a bad $\mathrm{M}$, the firm may not want a bad M to hire a good $\mathrm{W}$, because then a bad M stands to remain in the firm with greater probability, which reduces expected future profits. The optimal value of $\phi$ depends on the relative importance of the output and detection effects, which in turn depends on $\delta$.

\section{Alternative Solutions and Implementation}

The formal analysis leaves open how restricted communication compares to alternative policies, and to what extent the organization can implement the desired openness. We turn to these issues in Sections 6.1 and 6.2.

\footnotetext{
${ }^{12}$ It would be easy to distinguish the discount factors formally, but it appears that no additional testable predictions would result from doing so.
} 


\subsection{Alternative Solutions}

The abuse of personnel authority is recognized as a problem both among practitioners and in the more applied management literature. South and Matejka (1990), for example, observe that "Weak performing managers avoid selecting individuals who will threaten their status and contrast their own substandard performance. Surprisingly, they seem able to do this rather well". The academic literature, in contrast, appears not to have addressed this problem in any systematic way. ${ }^{13}$

South and Matejka suggest that in order to detect "multiple weak links", that is, chains of weak managers that develop when one weak manager hires another, firms can check indicators of unit performance. They note, however, that reliable indicators are often unavailable. Moreover, as our analysis has shown, a firm may still want to restrict communication even if performance can be observed. In what follows we discuss other solutions.

Centralization of personnel decisions: In response to the tendency of managers to make personnel decisions that serve their own rather than the firm's interests, firms may try to shift such decisions to a centralized personnel department. ${ }^{14}$ Indeed, the emergence of internal labor markets in American corporations in the mid-20th century, in part a result of pressure by unions that distrusted managers, was characterized by a shift toward more formalized and centralized personnel decisions (Jacoby 1984). But hierarchies exist precisely because it is efficient to delegate tasks, including personnel decisions, to managers; and there are limits to monitoring managers in what they do. In practice, "most line managers make the final employment or promotion decision" (South and Matejka 1990)

\footnotetext{
${ }^{13}$ We are not alone with this impression. Vredenburgh and Brender (1998), too, note that "Although much theoretical and empirical research has examined organizational power, virtually none has addressed the hierarchical abuse of power in organizations." An exception is the occasional mention in the literature that managers often prefer subordinates who are similar to themselves, or who are "yes men".

14 Shifting authority away from managers is, for the purposes of this paper, largely equivalent to monitoring managers' decisions more closely. In our model, this would be reflected in an increase in $k_{1}$, cf. Proposition 5.
} 
because their assessment of future subordinates is essential. ${ }^{15}$

Even if hiring decisions are made by a personnel department, managers still retain substantial influence over their subordinates' careers and may use it to their advantage as long as subordinates pose a threat to them (cf. footnote 4).

Employment guarantee: Another way to prevent the abuse of authority is to guarantee not to fire a manager regardless of bad news about him. Carmichael (1988) argues that tenure in academia protects senior faculty against being replaced by more productive assistant professors. This assures the incentive to recruit the most productive juniors. While lifetime employment may or may not be optimal in academia, employment guarantees are rarely offered in firms that have to survive in a competitive environment. ${ }^{16}$

In our simple model, which does not involve any moral hazard in production, an employment guarantee for $\mathrm{M}$ in the second period is inferior to a chain of command (unless open communication is strongly desired for other reasons, i.e. $\omega>>0$ ). While both policies prevent strategic recruiting, with an employment guarantee the organization cannot get rid of M if output is zero, which undermines M's incentive to recruit a good subordinate. That said, restrictions on skip-level communication, which are common in private firms, may be too costly to implement in other organizations such as universities. If it is impossible to prevent university boards from comparing the performance of senior and junior faculty members (since the performance is largely public anyway), then the institution of tenure may be the only feasible, if costly, solution.

Non-replacement rules: Many organizations follow a policy of never promoting an employee to the position of her immediate superior. If W cannot hope to get M's position as a direct consequence of communicating with $\mathrm{P}$, she will have much less incentive to do so, which reduces the threat of replacement for $\mathrm{M}$. The protection for $\mathrm{M}$ might be only

15 Cf. also Pinfield 1995, p.316: "In salaried employment systems [as opposed to blue-collar employment systems], managers typically have considerable discretion as to how jobs should be defined and which employee qualities would be most suited to performance of those jobs".

16 Well-known examples are partnerships in law, auditing and consulting firms. Similarly, lifetime employment has been a central element in the organization of large Japanese corporations. In both cases, however, there is trend away from employment guarantees. 
limited, though, for if $\mathrm{W}$ credibly informs $\mathrm{P}$ that $\mathrm{M}$ is unproductive, $\mathrm{M}$ will be fired even if $\mathrm{W}$ does not get promoted. Even if $\mathrm{W}$ has no specific interest in harming $\mathrm{M}$, she may communicate with $\mathrm{P}$ to make a good impression, hoping to get promoted to a different department sometime later.

Promotion by seniority: More effective in preventing a subordinate from competing for her boss's job is to promote employees by seniority rather than performance. Doeringer and Piore (1971) argue that the bureaucratic features of internal labor markets are necessary to provide experienced workers with an incentive to train younger workers: "the effectiveness of on-the-job training depends heavily upon the willingness of experienced workmen to teach new workers. Incumbent employees are thus in a position to frustrate this training process..." (p.84). Hence, "A certain degree of wage rigidity and job security is therefore necessary for on-the-job training to operate at all" (p.33).

Our discussion suggests that as remedies for the abuse of authority, hierarchical communication and promotion by seniority are substitutes. This may seem counterintuitive, as casual observation suggests that rigid internal labor markets often exhibit both. It is important, however, to distinguish between seniority-based promotions as a policy and in equilibrium: if a firm maintains a strict chain of command, managers making promotion decisions may have to choose from the employees one or two levels below them, whom they know, ignoring those at lower ranks. Thus, promotions can in equilibrium be correlated with seniority even if seniority is not an explicit criterion for promotion. In other words, hierarchical communication and promotion by seniority as policies can be substitutes even if observed hierarchical communication and promotions by seniority are positively related.

Job rotation: South and Matejka (1990) also mention job rotation as a possible remedy: "At middle and lower levels of management, it would be possible to utilize career job rotation to transfer management personnel at timely intervals thus retarding the development of [multiple weak links]."

At a closer look, however, the benefits of job rotation are ambiguous. Suppose there are two production teams, 1 and 2, that each consist of a manager $M_{i}$ and a worker $W_{i}$, $i=1,2$. Split the first period in two halves. In the first sub-period, $M_{i}$ recruits and works 
with $W_{i}$. Then the workers swap, and in the second sub-period $M_{i}$ works with $W_{j}, j \neq i$. At the end of the two sub-periods, each worker can give a report about each manager.

In this setup, each manager's payoff depends half on the worker he hires, and half on the worker hired by the other manager. The result is a free-riding effect that can go in either direction. A bad manager who without job rotation would actively seek to recruit a bad $\mathrm{W}$ by choosing $\alpha_{b}$ on the downward-sloping part of $C(\alpha)$ would now have less of an incentive to abuse his authority. Any other manager, however, would have less of an incentive to hire a good worker. The net effect is ambiguous and depends on $\alpha_{0}$, the ease with which the organization can hire productive managers.

\subsection{Implementation}

An important issue is how hierarchical communication can be implemented in practice; specifically, how employees can be prevented from communicating with their bosses' superiors. Organizational rules on communicating are part of the culture of an organization, and can be defined in general terms as "assumptions organizational members make about the right way to communicate in a given situation in their particular organization" (Gilsdorf 1998). A company's management can influence the organizational culture, including communication rules, in many ways.

First, the openness of communication depends on what De Long and Fahey (2000) call the "approachability" of superiors, which is shaped by both architecture and symbols. Lockers of blue-collar workers can be close or remote to the offices of management. People at different levels in the hierarchy may work in physical proximity to each other, or the location of an office may reflect the hierarchy, with top management on the top floors and lower-level employees on lower floors. ${ }^{17}$ Management can also influence communication through open- or closed-door policies and the use of information technology.

As De Long and Fahey point out, the ability to contact higher-level managers also depends on organizational practices, such as the frequency of staff meetings, and the

\footnotetext{
${ }^{17}$ See also Glauser (1984) and the references therein for evidence that "physical or structural inaccessibility is a deterrent to superior/subordinate interaction."
} 
participation of managers of non-adjacent hierarchy levels in the same meetings.

Second, in addition to physical and institutional barriers to communication, top managers can actively discourage employees from violating the chain of command. They can build a reputation for not talking to lower-level employees and not listening to their complaints about their supervisors. The firm can encourage such behavior by fostering an organizational culture based on the chain of command and the authority of supervisors. ${ }^{18}$ Top managers may also have an individual reason to ignore or punish a subordinate whose comments about her supervisor's competence identifies her as a "troublemaker", even if the information thus obtained is useful. ${ }^{19}$

Third, openness is affected by the ability of a subordinate to provide top management with convincing evidence that she is more qualified than her superior. This factor, too, is influenced by the firm's organizational procedures and policies. We conclude that while the openness of communication cannot be fine-tuned, there are many mechanisms that organizations can use to make it harder (or easier) for some members of the organization to communicate openly with each other, and top managers themselves can influence the openness of communication to a considerable extent.

\section{Conclusion}

In this paper we have proposed an incentive-based explanation for hierarchical communication. Managers who fear being replaced by their subordinates have an incentive to recruit and develop weaker but less dangerous subordinates. This incentive is mitigated

18 In line with this reasoning, the Bureau of National Affairs found in a survey of formal complaint procedures within firms that managers' decisions are almost always upheld by higher levels in response to complaints (Bureau of National Affairs 1979). An alternative explanation for this finding, however, would be that higher levels refrain from "undermining the authority" of supervisors because their trustworthiness is important for the subordinates' work morale, cf. Prendergast (1994).

19 Or as Caesar put it: "I love treason but hate a traitor" (Bartlett's 1992, p.88). Employees who make negative remarks about their superiors are likely to face similar retaliation as do whistle-blowers, even if complaints are justified (for evidence on retaliation against whistle-blowers, see Rothschild and Miethe 1999). 
if communication between subordinates and top management is disrupted. Trading off the benefits of open communication against the costs of suboptimal personnel decisions, firms may choose to restrict or even completely prohibit skip-level communication.

Our analysis suggests that the design of an intra-firm communication structure must take into account the firm's human resource practices and the employees' possible strategic behavior. As we have shown, the wage structure, the effectiveness of recruiting good line managers (which also depends on resources spent), the monitoring of personnel decisions, and job design, all affect the firm's optimal level of openness of communication.

It follows from our analysis that it is unwise to allow or even encourage communication between lower and higher levels in the hierarchy without considering the consequences for managers and their strategic responses. More generally, in organizations that do not restrict communication, the flow of information in equilibrium may be limited if people anticipate that what they say to others might be used against them. Similarly, if we interpret negative comments about the abilities of one's superior as a form of "disloyal" behavior, our results suggest that organizations take considerable risks when tolerating or even encouraging disloyalty. While disloyalty may be directly beneficial in helping to detect and replace unproductive employees, harm is caused in an indirect way through the counter-productive activities of supervisors who see their positions threatened by disloyal subordinates. 


\section{References}

Adams, Scott (1996): Dogbert's Top Secret Management Handbook, New York (Harper Collins)

Baird, John E. (1977): The Dynamics of Organizational Communication, Harper \& Row

Baker, George P.; Michael C. Jensen and Kevin J. Murphy (1988): "Compensation and Incentives: Practice vs. Theory", Journal of Finance, Vol. 43, pp. 593-616

Barney, Jay and Ricky Griffin (1992): The Management of Organizations, Boston and Toronto (Houghton Mifflin)

Bartlett, John and Justin Kaplan (eds.) (1992): Bartlett's Familiar Quotations, $16^{\text {th }}$ ed. (Little, Brown)

Bertrand, Marianne (1998): "From the Invisible Handshake to the Invisible Hand?", mimeo, Harvard

Bettenhausen, Kenneth L. and Donald B. and Fedor (1997): "Peer and Upward Appraisals: a Comparison of Their Benefits and Problems", Group \& Organization Management Vol. 22, pp. 236-263

Bolton, Patrick and Mathias Dewatripont (1994): "The Firm as a Communication Network", Quarterly Journal of Economics, Vol. 109, pp. 809-839

Brutus, Stéphane, John W. Fleenor and Manuel London (1998): "Elements of Effective 360-Degree Feedback", in: Tornow and London (1998), pp. 11-27

Bureau of National Affairs (1979): "Policies for Unorganized Employees", Personnel Policies Forum Survey No. 125

Carmichael, Lorne H. (1988): "Incentives in Academics: Why is there Tenure?", Journal of Political Economy, Vol. 96, pp. 453-72

De Long, David W. and Liam Fahey (2000): "Diagnosing Cultural Barriers to Knowledge Management", Academy of Management Executive,Vol. 14, pp. 113-127 
Dalton, Maxine (1998): "Best practices - Five Rationales for Using 360-Degree Feedback in Organizations", in: Tornow and London (1998), pp. 59-77

Doeringer, Peter and Michael Piore (1971): Internal Labor Markets and Manpower Analysis, Lexington, MA (Heath)

Falconi, Robert (1997): "When Open-Door Policies Fail", Financial Executive, Vol. 13/5, pp. $14-15$

Fayol, Henri (1916): Administration Industrielle et Générale, Paris

Friebel, Guido and Michael Raith (1999): "Strategic Recruiting and the Chain of Command - On the Abuse of Authority in Internal Labor Markets", mimeo, University of Chicago

Gilsdorf, Jeanette W. (1998): "Organizational Rules on Communicating: How Employees Are - and Are Not - Learning the Ropes", Journal of Business Communication Vol. 35, pp. 173-201

Glauser, Michael J. (1984) "Upward Information Flow in Organizations: Review and Conceptual Analysis", Human Relations Vol. 37, pp. 613-643

Jacoby, Sanford M. (1984): "The Development of Internal Labor Markets in American Manufacturing Firms", in: Paul Osterman (ed.), Internal Labor Markets, MIT Press

Kiechel, Walter (1989): "When Subordinates Evaluate the Boss", Fortune, June 19, pp. 201-202

Lazear, Edward R. (1981): “Agency, Earnings Profiles, Productivity, and Hours Restrictions", American Economic Review, Vol. 71, pp. 606-620

Lazear, Edward R. and Sherwin Rosen (1981): "Rank-order Tournaments as Optimum Labor Contracts", Journal of Political Economy, Vol. 89, pp. 841-64

Lillico, T.M. (1972): Managerial Communication, Pergamon Press 
Milgrom, Paul (1988): "Employment Contracts, Influence Activities, and Efficient Organization Design", Journal of Political Economy, Vol. 96, pp. 42-60

Milgrom, Paul and John Roberts (1990): "The Efficiency of Equity in Organizational Decision Processes", American Economic Review Papers and Proceedings, Vol. 80, pp. $154-159$

Prendergast, Canice (1994): “Authority and Performance Evaluation", mimeo, University of Chicago, Graduate School of Business

Qian, Yingyi (1994): "Incentives and Loss of Control in an Optimal Hierarchy", Review of Economic Studies, Vol. 61, pp. 527-44.

Radner, Roy (1993): “The Organization of Decentralized Information Processing”, Econometrica, Vol. 61, pp. 1109-1146

Randolph and Finch (1977): "The Relationship Between Organization Technology and the Direction and Frequency Dimensions of Task Communications", Human Relations

Rothschild, Joyce and Terance Miethe (1999): "Whistle-Blower Disclosures and Management Retaliation", Work and Occupations, Vol. 26, pp. 107-128

Salop, Joanne and Steven Salop (1976): "Self-Selection and Turnover in the Labor Market", Quarterly Journal of Economics, Vol. 90, pp. 619-627

South, John C. and Ken Matejka (1990): "Unmasking Multiple Weak Links in the Chain of Command", Management Decision 28, no.3

Tornow, Walter W., Manuel London and CCL Associates (eds.) (1998): Maximizing the Value of 360-Degree Feedback, (Jossey-Bass Publishers)

Vredenburgh, Donald and Yael Brender (1998): "The Hierarchical Abuse of Power in Work Organizations", Journal of Business Ethics 17, 1337-1347

Wilson, Donald O. (1992): "Diagonal Communication Links Within Organizations", Journal of Business Communication 29, pp. 129-143 


\section{Appendix: Proofs}

\section{Proof of Proposition 1:}

Preliminaries: notation and updating procedure

1. For a given belief $\mathbf{p}=\left(p_{g g}, p_{g b}, p_{b g}, p_{b b}\right)$ about the composition of the (M,W)-team (cf. Section 3.2), denote by $p_{M}(\mathbf{p})$ and $p_{W}(\mathbf{p})$ the marginal probabilities that $\mathrm{M}$ and $\mathrm{W}$ are good, respectively. That is, $p_{M}(\mathbf{p})=p_{g g}+p_{g b}$ and $p_{W}(\mathbf{p})=p_{g g}+p_{b g}$.

2. In some situations the types of $\mathrm{M}$ and $\mathrm{W}$ can be seen as stochastically independent. Here, if e.g. $\operatorname{Prob}(\mathrm{M}=\mathrm{g})=a$ and $\operatorname{Prob}(\mathrm{W}=\mathrm{g})=b$, we will use the shorthand notation $[a, b]:=(a b, a(1-b),(1-a) b,(1-a)(1-b))$ for a team belief. Then, the expected output $[a, b] \mathbf{q}$ is increasing in both $a$ and $b$. Moreover, the assumption $q_{g b} \geq q_{b g}$, i.e. that $\mathrm{M}$ is relatively more important than $\mathrm{W}$, implies that $[a, b] \mathbf{q} \geq[b, a] \mathbf{q}$ if and only if $a \geq b$.

3. A good $\mathrm{M}$ is hired with probability $\alpha_{0}$, and hires a good $\mathrm{W}$ with probability $\alpha_{g}$. A bad M hires a good W with probability $\alpha_{b}$. Hence, the prior for P's belief about the team is $\mathbf{p}_{\mathbf{1}}=\left(\alpha_{0} \alpha_{g}, \alpha_{0}\left(1-\alpha_{g}\right),\left(1-\alpha_{0}\right) \alpha_{b},\left(1-\alpha_{0}\right)\left(1-\alpha_{b}\right)\right)$.

4. Next, consider how the signals $y$ and $z$ affect P's beliefs, starting from any prior $\mathbf{p}=$ $\left(p_{g g}, p_{g b}, p_{b g}, p_{b b}\right)$. If $\mathrm{W}$ reveals that she is good and $\mathrm{M}$ is bad, $\mathrm{P}$ has perfect information about (M,B). Hence, P's updated belief about the team is $t^{d}(\mathbf{p})=(0,0,1,0)$. On the other hand, if $z=c$, then, her posterior is

$$
t^{c}(\mathbf{p})=\frac{1}{1-\phi p_{b g}}\left(p_{g g}, p_{g b},(1-\phi) p_{b g}, p_{b b}\right)
$$

Depending on whether $y=1$ or $y=0$ is observed, the posterior of $\mathbf{p}$ is

$$
\begin{aligned}
t^{1}(\mathbf{p}) & =\frac{1}{\mathbf{p q}}\left(p_{g g} q_{g g}, p_{g b} q_{g b}, p_{b g} q_{b g}, p_{b b} q_{b b}\right) \quad \text { or } \\
t^{0}(\mathbf{p}) & =\frac{1}{1-\mathbf{p q}}\left(p_{g g}\left(1-q_{g g}\right), p_{g b}\left(1-q_{g b}\right), p_{b g}\left(1-q_{b g}\right), p_{b b}\left(1-q_{b b}\right)\right) .
\end{aligned}
$$

5. Finally, we determine how P's beliefs are affected by her decision regarding M. If $\mathrm{P}$ promotes $\mathrm{W}$ and a new $\mathrm{W}$ is hired, her belief is

$$
t^{p}(\mathbf{p})=\left[p_{W}(\mathbf{p}), \alpha_{0}\right]
$$


If she hires a new $\mathrm{M}$, this $\mathrm{M}$ is good with probability $\alpha_{0}$. By assumption, $\mathrm{W}$ is retained if and only if she is good (the probability of which is $p_{W}(\mathbf{p})$ ). Otherwise, a new $\mathrm{W}$ is hired and is good with probability $\alpha_{0}$. Thus, P's belief upon hiring an new $\mathrm{M}$ is

$$
t^{h}(\mathbf{p})=\left[\alpha_{0}, p_{W}(\mathbf{p})+\alpha_{0}\left(1-p_{W}(\mathbf{p})\right)\right]=\left[\alpha_{0}, p_{g g}+p_{b g}+\alpha_{0}\left(p_{g b}+p_{b b}\right)\right]
$$

If $\mathrm{P}$ retains $\mathrm{M}$, her belief is

$$
t^{r}(\mathbf{p})=\left(p_{g g}+\alpha_{0} p_{g b},\left(1-\alpha_{0}\right) p_{g b}, p_{b g}+\alpha_{0} p_{b b},\left(1-\alpha_{0}\right) p_{b b}\right)
$$

This transition function is obtained as follows: if the team $(\mathrm{M}, \mathrm{W})$ is $(\mathrm{g}, \mathrm{g})$ or $(\mathrm{b}, \mathrm{g})$, the team is not changed if $\mathrm{M}$ is retained, since $\mathrm{M}$ always retains a good $\mathrm{W}$. On the other hand, if the team is $(\mathrm{g}, \mathrm{b})$ or $(\mathrm{b}, \mathrm{b})$, then a new $\mathrm{W}$ is hired, in which case the composition of the team remains unchanged with probability $\left(1-\alpha_{0}\right)$ and is "upgraded" (from (b,b) to $(\mathrm{b}, \mathrm{g})$ or from $(\mathrm{g}, \mathrm{b})$ to $(\mathrm{g}, \mathrm{g})$, respectively) with probability $\alpha_{0}$.

\section{$P$ 's best response:}

We determine P's best response to M's strategy under the assumption that $\alpha_{g} \geq \alpha_{b}$. Later, we show that $\alpha_{g} \geq \alpha_{b}$ must hold in any equilibrium of the game, which establishes uniqueness of the equilibrium for any set of parameters.

1. If $z=d, \mathrm{P}$ knows that $\mathrm{M}$ is bad and $\mathrm{W}$ is good. If $\mathrm{P}$ promotes $\mathrm{W}$, her new expected team is $t^{p}((0,0,1,0))=\left[1, \alpha_{0}\right]$. If she hires a new $\mathrm{M}$, her new expected team is $t^{h}((0,0,1,0))=\left[\alpha_{0}, 1\right]$. If she retains $\mathrm{M}$, her belief is $t^{r}(0,0,1,0)=(0,0,1,0)=[0,1]$. Since $\left[1, \alpha_{0}\right] \mathbf{q} \geq\left[\alpha_{0}, 1\right] \mathbf{q} \geq[0,1] \mathbf{q},($ cf. Preliminaries, point 2$)$, it follows that to promote $\mathrm{W}$ is $\mathrm{P}$ 's best action.

2. If $z=c$ and $y=0$, then $\mathrm{P}$ will hire a new $\mathrm{M}$, retain him, or promote $\mathrm{W}$, depending on which of the expected second-period payoffs $t^{h}\left(t^{c}\left(t^{0}\left(\mathbf{p}_{\mathbf{0}}\right)\right)\right) \mathbf{q}, t^{r}\left(t^{c}\left(t^{0}\left(\mathbf{p}_{\mathbf{0}}\right)\right)\right) \mathbf{q}$, or $t^{p}\left(t^{c}\left(t^{0}\left(\mathbf{p}_{\mathbf{0}}\right)\right)\right) \mathbf{q}$ is maximal. These payoffs have the common denominator

$$
\tau_{0}=1-\alpha_{0}\left[q_{g g} \alpha_{g}+\left(1-\alpha_{g}\right) q_{g b}\right]-\left(1-\alpha_{0}\right)\left[\alpha_{b}\left(q_{b g}+\phi\left(1-q_{b g}\right)\right)+\left(1-\alpha_{b}\right) q_{b b}\right]>0
$$

hence it suffices to compare the numerators only. To simplify the resulting expressions, define

$$
\mu=q_{g g}+q_{b b}-q_{g b}-q_{b g}>0, \quad \rho=a_{0} \mu+q_{g b}-q_{b b}>0, \quad \sigma=\left(1-\alpha_{0}\right)\left(q_{g b}-q_{b g}\right) .
$$


Using (10) and (12)-(15), hiring is preferred to promoting if

$$
\begin{aligned}
& \alpha_{0}\left[\left(1-\alpha_{0}\right)\left(1-\alpha_{b}\right)\left(1-q_{b b}\right)+\alpha_{0}\left(1-\alpha_{g}\right)\left(1-q_{g b}\right)\right] \rho \\
& -\left[(1-\phi)\left(1-\alpha_{0}\right) \alpha_{b}\left(1-q_{b g}\right)+\alpha_{0} \alpha_{g}\left(1-q_{g g}\right)\right] \sigma>0 .
\end{aligned}
$$

and hiring is preferred to retaining if

$$
\begin{aligned}
& \alpha_{0}\left(1-\alpha_{0}\right)\left\{\alpha_{b}(1-\phi)\left(1-q_{b g}\right)\left(q_{g g}-q_{b g}\right)-\alpha_{g}\left(1-q_{g g}\right)\left(q_{g g}-q_{b g}\right)\right. \\
& \left.\quad+\rho\left[\left(1-\alpha_{g}\right)\left(q_{g b}-q_{b b}\right)+\left(\alpha_{g}-\alpha_{b}\right)\left(1-q_{b b}\right)\right]\right\}>0 .
\end{aligned}
$$

We discuss in 4. below for which parameters (16) and (17) are satisfied.

3. If $z=c$ and $y=1$, P's optimal action depends on which of $t^{h}\left(t^{c}\left(t^{1}\left(\mathbf{p}_{\mathbf{0}}\right)\right)\right) \mathbf{q}$, $t^{r}\left(t^{c}\left(t^{1}\left(\mathbf{p}_{\mathbf{0}}\right)\right)\right) \mathbf{q}$ and $t^{p}\left(t^{c}\left(t^{1}\left(\mathbf{p}_{\mathbf{0}}\right)\right)\right) \mathbf{q}$ is maximal. These payoffs have the common denominator

$$
\tau_{1}=\left(1-\alpha_{0}\right)\left(1-\alpha_{b}\right) q_{b b}+\alpha_{b}\left(1-\alpha_{0}\right)(1-\phi) q_{b g}+\alpha_{0}\left[q_{g b}+\alpha_{g}\left(q_{g g}-q_{g b}\right)\right]>0
$$

hence it suffices to compare the numerators only. To simplify the resulting expressions, define $\psi=q_{g b}-q_{b g}+\alpha_{0}\left(q_{g g}-q_{g b}\right)$. Using (10)-(11) and (13)-(15), retaining is preferred to promoting if

$$
\begin{aligned}
& \alpha_{0}\left(1-\alpha_{g}\right)\left\{\alpha_{0}\left[q_{g g}\left(q_{g g}-q_{g b}\right)+q_{g b} \mu\right]-\left[q_{g g}\left(q_{g g}-q_{g b}\right)-q_{g b}\left(q_{g b}-q_{b b}\right)\right]\right\} \\
& +\left(1-\alpha_{0}\right)\left\{\alpha_{0}\left[q_{g g}\left(q_{g g}-q_{g b}-q_{b g}\right)+q_{b g}^{2}+\left(1-\alpha_{0}\right) q_{b g}\left(q_{g g}-q_{g b}\right)\right]+\left[\alpha_{0}-\alpha_{b}(1-\phi)\right] q_{b g} \psi\right\} \\
& >0
\end{aligned}
$$

or equivalently

$$
\begin{aligned}
& \alpha_{0}\left[\alpha_{0}\left(1-\alpha_{0}\right) q_{g g}\left(q_{g b}-q_{b g}\right)+\left(1-\alpha_{0}\right)\left(q_{g b}-q_{b g}\right)^{2}+q_{g b}\left(1-\alpha_{0}\right)\left(q_{b g}-q_{b b}\right)\right] \\
& +\left(1-\alpha_{0}\right)\left(\alpha_{0}-\alpha_{b}\right) q_{b g} \psi+\left(1-\alpha_{0}\right) \alpha_{b} \phi q_{b g} \psi \\
& +\alpha_{0} \alpha_{g}\left(1-\alpha_{0}\right)\left[q_{g g}^{2}-q_{g b}^{2}-q_{g b}\left(q_{b g}-q_{b b}\right)\right]+\alpha_{0}\left(\alpha_{0}^{2}-\alpha_{g}\right) q_{g b}\left(q_{g g}-q_{b g}\right)>0,
\end{aligned}
$$

and retaining is preferred to hiring if

$$
\begin{gathered}
\alpha_{0}\left(1-\alpha_{0}\right)\left\{\left(q_{g b}-q_{b b}\right)^{2}+\alpha_{b} q_{b g}\left(q_{g g}-q_{b g}\right) \phi+\left(\alpha_{g}-\alpha_{b}\right)\left[\left(q_{g g}-\alpha_{0} q_{g b}\right) \mu+\left(q_{g g}-q_{g b}\right)\left(q_{g b}-q_{b b}\right)\right]\right. \\
\left.+\mu\left[\alpha_{0}\left(1-\alpha_{b}\right)\left(q_{g b}-q_{b b}\right)+\alpha_{b}\left(q_{g g}+q_{g b}-q_{b g}-q_{b b}\right)\right]\right\}>0 .
\end{gathered}
$$


4. The principal's equilibrium strategy takes the form described in Proposition 1 if (16)-(20) all hold. Inspection shows that (20) always holds. Given the assumption $\alpha_{0} \geq \alpha_{b}$, a sufficient condition for both (16) and (17) is $q_{g g}=1$. A sufficient condition for (18) and (19) is $q_{g b}+q_{b g}<q_{g g}$, the assumption stated in the proposition: since the lefthand sides of both inequalities are linear in $\alpha_{g}$, the minimum of each expression is attained at either $\alpha_{g}=0$ or $\alpha_{g}=1$. If $\alpha_{g}=0$, then (19) is satisfied, whereas if $\alpha_{g}=1,(18)$ is satisfied whenever $q_{g b}+q_{b g}<q_{g g}$. M's best response: Given P's strategy, the probability of retention is $P_{r e t}(\alpha)=\alpha q_{g g}+(1-\alpha) q_{g b}$ for a good M and $P_{r e t}(\alpha)=\alpha(1-\phi) q_{b g}+(1-\alpha) q_{b b}$ for a bad M. After substituting these expressions into (3), maximization with respect to $\alpha$ leads to the expressions for $\alpha_{g}$ and $\alpha_{b}$ stated in the proposition.

\section{Uniqueness:}

Since P's best response was derived for any $\alpha_{g} \geq \alpha_{b}$, the equilibrium derived is unique unless there exists an equilibrium in which $\alpha_{g}<\alpha_{b}$. This would require that $\mathrm{P}$ provides negative incentives, i.e. that she retains $\mathrm{M}$ if $y=0$ and $z=c$, and fires him if $y=1$. For such an equilibrium to exist in turn requires that for some $\phi$, both (17) and (20) be negative. We show that this can never be the case. To see this, notice that the numerator in $(17)$ is decreasing in $\phi$, while the numerator of (20) is increasing in $\phi$. Specifically, (17) can be negative only if $\phi$ exceeds

$$
\frac{\rho\left[q_{g b}-q_{b b}+\alpha_{g}\left(1-q_{g b}\right)-\alpha_{b}\left(1-q_{b b}\right)\right]+\left(q_{g g}-q_{b g}\right)\left[\alpha_{b}\left(1-q_{b g}\right)-\alpha_{g}\left(1-q_{g g}\right)\right]}{\alpha_{b}\left(1-q_{b g}\right)\left(q_{g g}-q_{b g}\right)} .
$$

However, substituting this value for $\phi$ into the Numerator of $(20)$ yields $\alpha_{0}\left(1-\alpha_{0}\right)$ times

$$
\frac{\left(q_{g b}-q_{b b}+\alpha_{0} \mu\right)\left[q_{g b}-\alpha_{b} q_{b g}-\left(1-\alpha_{b}\right) q_{b b}\right]+\alpha_{g}\left[\left(q_{g g}-q_{g b}\right)\left(q_{g g}-q_{b g}\right)+\left(1-\alpha_{0}\right)\left(q_{g b}-q_{b g}\right) \mu\right]}{1-q_{b g}},
$$

which is positive, so that (20) is also positive for any larger $\phi$.

Comment on other equilibria: If (16)-(20) are not all satisfied, different equilibria result, where for any set of parameters there is a unique equilibrium. Depending on which of (16)-(20) hold, we obtain equilibria in which P's strategy in the case $z=c$ is as described in the following table: 


\begin{tabular}{|ccc|c|c|}
\hline \multicolumn{2}{|c|}{ Conditions satisfied } & \multicolumn{2}{c|}{ P's action } \\
\hline$(16)$ & $(17)$ & $(18),(19)$ & $y=0$ & $y=1$ \\
yes & yes & yes & hire & retain \\
\hline yes & yes & no & hire & promote \\
yes & no & yes & retain & retain \\
yes & no & no & retain & promote \\
no & yes & yes & promote & retain \\
no & yes & no & promote & promote \\
no & no & yes & promote or retain & retain \\
no & no & no & promote or retain & promote \\
\hline
\end{tabular}

In the last two cases shown in the table, $\mathrm{P}$ prefers to retain $\mathrm{M}$ instead of promoting $\mathrm{W}$ if and only if $t^{r}\left(t^{c}\left(t^{0}\left(\mathbf{p}_{\mathbf{0}}\right)\right)\right) \mathbf{q}>t^{p}\left(t^{c}\left(t^{0}\left(\mathbf{p}_{\mathbf{0}}\right)\right)\right) \mathbf{q}$. Thus, in general there exist three types of equilibria that differ in P's action when $z=c$ : first, the one stated in Proposition 1; second, one in which $\mathrm{P}$ always retains $\mathrm{M}$ irrespective of output; and third, equilibria in which $\mathrm{P}$ promotes $\mathrm{W}$ if either $y=0$ or $y=1$ or in both cases, even if $\mathrm{P}$ does not receive a signal that $\mathrm{W}$ is good. As we argue in the text, the second type of equilibrium leads to maximal abuse of authority since $\mathrm{M}$ can only lose from having a good $\mathrm{W}$; whereas the third type of equilibrium does not make much sense economically.

Proof of Proposition 2: In equilibrium, the firm's ex ante expected composition of the $(\mathrm{M}, \mathrm{W})$-team after the first period is

$$
\begin{gathered}
E\left(\mathbf{p}_{\mathbf{2}}\right)=\phi\left(1-\alpha_{0}\right) \alpha_{b} t^{p}\left(t^{d}\left(\mathbf{p}_{\mathbf{1}}\right)\right) \\
+\left[1-\phi\left(1-\alpha_{0}\right) \alpha_{b}\right]\left[\left(t^{c}\left(\mathbf{p}_{\mathbf{1}}\right) \mathbf{q}\right) t^{r}\left(t^{1}\left(t^{c}\left(\mathbf{p}_{\mathbf{1}}\right)\right)\right)+\left(1-t^{c}\left(\mathbf{p}_{\mathbf{1}}\right) \mathbf{q}\right) t^{h}\left(t^{0}\left(t^{c}\left(\mathbf{p}_{\mathbf{1}}\right)\right)\right)\right]
\end{gathered}
$$

The first term is the probability that $\mathrm{W}$ is promoted, multiplied by the associated expected team belief. The second term covers the case $z=c$, where $\mathrm{M}$ is retained with (conditional) probability $t^{c}\left(\mathbf{p}_{\mathbf{1}}\right) \mathbf{q}$ and fired with probability $1-t^{c}\left(\mathbf{p}_{\mathbf{1}}\right) \mathbf{q}$. Plugging $\mathbf{p}_{\mathbf{2}}$ into (4), the firm's expected profit can be expressed in the form $\pi=A+B \alpha_{b}(\phi)+C \phi \alpha_{b}(\phi)+D \phi$, where

$$
A=\alpha_{0} \alpha_{g} q_{g g}+\alpha_{0}\left(1-\alpha_{g}\right) q_{g b}+\left(1-\alpha_{0}\right) q_{b b}-(1+\delta)\left(r_{M}+r_{W}\right)
$$




$$
\begin{aligned}
& +\delta\left\{\alpha_{0}\left(1-\alpha_{0}\right)^{2}\left[\left(1-\alpha_{g}\right)\left(q_{g b}-q_{b b}\right) q_{g b}+q_{b b}^{2}+q_{g b}\left(1-q_{b b}\right)+\alpha_{g}\left(q_{b g}-q_{b b}\right)\right]\right. \\
& +\alpha_{0}^{2} q_{g g}+\alpha_{0}^{2}\left(1-\alpha_{0}\right)\left[\alpha_{g} q_{g g}+\left(1-\alpha_{g}\right) q_{g b}\right]+\left(1-\alpha_{0}\right)\left[\alpha_{0} q_{b g}+\left(1-\alpha_{0}\right) q_{b b}\right] \\
& \left.+\alpha_{0}\left(1-\alpha_{0}\right)\left(q_{g g}-q_{b g}\right)\left[\alpha_{g}\left(q_{g g}-\alpha_{0} q_{g b}\right)+\alpha_{0}\left(q_{g b}-q_{b b}\right)\right]\right\}>0 \\
B= & \left(1-\alpha_{0}\right)\left\{\left(q_{b g}-q_{b b}\right)+\delta\left(1-\alpha_{0}\right)\left[\alpha_{0} \mu+q_{b g}-q_{b b}+\alpha_{0} q_{b b}\left(q_{g b}-q_{b b}\right)\right]\right. \\
& \left.-\delta\left(q_{b g}-\alpha_{0} q_{b b}\right) \alpha_{0}\left(q_{g g}-q_{b g}\right)\right\}<>0, \\
C= & \left(1-\alpha_{0}\right) \delta\left[\left(1-\alpha_{0}\right)\left(q_{g b}-q_{b g}\right)+q_{b g} \alpha_{0}\left(q_{g g}-q_{b g}\right)\right]>0, \quad \text { and } \\
D= & (1+\delta) \omega>0,
\end{aligned}
$$

and A through D are independent of $\phi$ and $\alpha_{b}$. Differentiate $\pi\left(\phi, \alpha_{b}(\phi)\right)$ twice with respect to $\phi$ to obtain $d^{2} \pi / d \phi^{2}=2 C \partial \alpha_{b} / \partial \phi$, where $C$ is positive, and according to Proposition $1, \alpha_{b}$ is decreasing in $\phi$. Hence, $\pi$ is concave in $\phi$.

Proof of Proposition 3: If $k_{1}=0$, then from Proposition 1 it follows that for any $\phi \geq 1-q_{b b} / q_{b g}, \alpha_{b}$ equals zero. Thus, expressing $\pi$ and $\alpha_{b}$ as functions of $\phi$, we have $\pi(0)-\pi(\phi)=B\left[\alpha_{b}(0)-\alpha_{b}(\phi)\right]-C \alpha_{b}(\phi)=B \alpha_{b}(0)$, using the notation of (21). The middle term in the \{\} -brackets in $B$ is positive, and if $\delta \leq 1$, the first term exceeds the third, so that $B$ is positive.

Proof of Proposition 4: With a bonus $b$ paid to $\mathrm{M}$ whenever $y=1$, a raise $\Delta_{r}$ for $\mathrm{M}$ in the second period if $\mathrm{M}$ is retained, and a severance payment $s$ that is paid whenever $\mathrm{M}$ is fired even though $y=1$ (which can happen only if $\mathrm{M}$ is bad), straightforward generalization of M's payoff function (3) leads to the recruiting efforts

$$
\begin{gathered}
\alpha_{g}=\frac{1}{2\left(k_{0}+k_{1}\right)}\left[2 k_{1}+\left(q_{g g}-q_{g b}\right) b+\delta\left(q_{g g}-q_{g b}\right)\left(r_{M}-r_{M}+\Delta_{r}\right)\right] \quad \text { and } \\
\alpha_{b}=\frac{1}{2\left(k_{0}+k_{1}\right)}\left[2 k_{1}+\left(q_{b g}-q_{b b}\right) b+\delta\left((1-\phi) q_{b g}-q_{b b}\right)\left(r_{M}-r_{M}+\Delta_{r}\right)+\phi q_{b g} s\right] .
\end{gathered}
$$

Moreover, the firm's profit function contains the terms

$$
-\mathbf{p}_{\mathbf{1}} \mathbf{q} b-\phi\left(1-\alpha_{0}\right) \alpha_{b} q_{b g} s-\delta\left(1-\phi\left(1-\alpha_{0}\right) \alpha_{b}\right)\left(t^{c}\left(\mathbf{p}_{\mathbf{1}}\right) \mathbf{q}\right) \Delta_{r}
$$

in addition to (21). Then, because

$$
\delta \frac{\partial \alpha_{g}}{\partial b}=\frac{\partial \alpha_{g}}{\partial \Delta_{r}}, \quad \delta \frac{\partial \alpha_{b}}{\partial b}=\frac{\partial \alpha_{b}}{\partial \Delta_{r}}+\delta \frac{\partial \alpha_{b}}{\partial s}, \quad \text { and } \quad \delta \frac{\partial \pi}{\partial b}=\frac{\partial \pi}{\partial \Delta_{r}}+\delta \frac{\partial \pi}{\partial s},
$$


it follows that

$\delta\left(\frac{\partial \pi}{\partial b}+\frac{\partial \pi}{\partial \alpha_{b}} \frac{\partial \alpha_{b}}{\partial b}+\frac{\partial \pi}{\partial \alpha_{g}} \frac{\partial \alpha_{g}}{\partial b}\right)=\frac{\partial \pi}{\partial \Delta_{r}}+\frac{\partial \pi}{\partial \alpha_{b}} \frac{\partial \alpha_{b}}{\partial \Delta_{r}}+\frac{\partial \pi}{\partial \alpha_{g}} \frac{\partial \alpha_{g}}{\partial \Delta_{r}}+\delta\left(\frac{\partial \pi}{\partial s}+\frac{\partial \pi}{\partial \alpha_{b}} \frac{\partial \alpha_{b}}{\partial s}+\frac{\partial \pi}{\partial \alpha_{g}} \frac{\partial \alpha_{g}}{\partial s}\right)$

which is the statement of the proposition.

Proof of Proposition 5: Assuming that the optimal $\phi^{*}$ is interior, this $\phi$ is given by the first-order condition

$$
\frac{d \pi}{d \phi}=C \alpha_{b}(\phi)+D+(B+C \phi) \frac{\partial \alpha_{b}(\phi)}{\partial \phi}=0
$$

in the notation of (21). Since $\pi$ is concave in $\phi$, it follows that $d \phi^{*} / d x$, the response of the optimal $\phi$ to a change in any parameter $x$ of the model, has the same sign as $d^{2} \pi /(d \phi d x)$, which is obtained by differentiating (22) with respect to $x$.

For parts (i) through (iii) of the proposition, notice that in (22), the parameters $r_{M}$, $k_{0}$ and $k_{1}$ affect only $\alpha_{b}$ but not $B, C$ or $D$. Differentiating (22) and substituting for $(B+C \phi)$ from $(22)$, we obtain

$$
\frac{d^{2} \pi}{d \phi d x}=C \frac{\partial \alpha_{b}}{\partial x}+(B+C \phi) \frac{\partial^{2} \alpha_{b}}{\partial \phi \partial x}=C\left(\frac{\partial \alpha_{b}}{\partial x}-\frac{\alpha_{b}}{\partial \alpha_{b} / \partial x} \frac{\partial^{2} \alpha_{b}}{\partial \phi \partial x}\right)-\frac{D}{\partial \alpha_{b} / \partial x} \frac{\partial^{2} \alpha_{b}}{\partial \phi \partial x} .
$$

Evaluating (23) for $r_{M}, k_{0}$ and $k_{1}$ in place of $x$, we get

$$
\begin{gathered}
\frac{d^{2} \pi}{d \phi d r_{M}}=-\frac{1}{r_{M}-r_{W}}\left(\frac{k_{1}}{k_{0}+k_{1}} C+D\right)<0, \quad \frac{d^{2} \pi}{d \phi d k_{0}}=\frac{D}{k_{0}+k_{1}} \geq 0 \\
\text { and } \frac{d^{2} \pi}{d \phi d k_{1}}=\frac{C+D}{k_{0}+k_{1}}>0,
\end{gathered}
$$

since $C$ is positive and $D$ is nonnegative.

Part (iv): A change in $\alpha_{0}$ affects $B$ and $C$ in (22) but not $\alpha_{b}$. Therefore, we have

$$
\frac{d^{2} \pi}{d \phi d \alpha_{0}}=\frac{\partial C}{\partial \alpha_{0}} \alpha_{b}+\left(\frac{\partial B}{\partial \alpha_{0}}+\frac{\partial C}{\partial \alpha_{0}} \phi\right) \frac{\partial \alpha_{b}}{\partial \phi}=\frac{1}{C}\left[\left(C \frac{\partial B}{\partial \alpha_{0}}-B \frac{\partial C}{\partial \alpha_{0}}\right) \frac{\partial \alpha_{b}}{\partial \phi}-\frac{\partial C}{\partial \alpha_{0}} D\right]
$$

after substituting for $\alpha_{b}$ from (22). Here, the sign of the term in ()-parentheses on the right-hand side is indeterminate, whereas $\partial C / \partial \alpha_{0}$ is negative, since both factors of $C$ are decreasing in $\alpha_{0}$. Thus, $\phi^{*}$ is increasing in $\alpha_{0}$ if $D=(1+\delta) \omega$ is sufficiently large. - Part (v) is obvious, as from $(21), d^{2} \pi /(d \phi d \omega)=1+\delta$. 